\title{
Clinical Identification of High-Risk Elbow
}

\begin{tabular}{|l|l|}
\hline A. & Aronstam \\
\hline P. & Wassef \\
\hline
\end{tabular}

Treolar Haemophilia Centre, Lord Mayor Treloar Hospital, Alton, Hants, United Kingdom

A.Aronstam, Treloar Haemophilia Centre, Lord Mayor Treloar Hospital, GU34 1RQ Alton, Hants (United Kingdom) 120 consecutive elbow bleeds occurring in haemophiliacs who received $11-16 \mathrm{U} / \mathrm{kg}$ of factor VIII on presentation were studied. 25 bleeds (21\%) were retransfused within $48 \mathrm{~h}$ because of extension of bleedings or poor progress. Bleeds were treated by members of the same team using consistent guidelines for local mangagement and retransfusion. The age of the patient, baseline restricted movement of the joint and targeting into the joint did not significantly affect the likelihood of retransfusion nor did presentation with stiffness or a history of trauma. However, $15(60 \%)$ of the bleeds which were retransfused presented with pain and $20(80 \%)$ were tender at presentation. These figures contrasted with those for bleeds which were not retransfused of 27 $(28.4 \%)$ and $36(37.9 \%)$. The differences were significant $(\chi 2=12.46 ; p<0.0005)$. 18 $(72 \%)$ of retransfused bleeds presented with less than $50 \%$ of normal movement against $20(21 \%)$ who were not retransfused. This difference was also significant $(\chi 2=21.44 ; p<0.0005)$. The time taken from the onset of bleeding until the initial transfusion was not a significant factor up to $3 \mathrm{~h}$ from the onset of the bleed but then became marginally significant $\left(\chi^{2}=3.97 ; \mathrm{p}<0.5\right)$.

Conclusion

Elbow bleeds presenting with pain, tenderness and/or more than $50 \%$ restriction of movement and those presenting more than $3 \mathrm{~h}$ after the start of bleeding should be considered for higher initial doses of factor VIII. 